\title{
Challenges Facing Clinical Research: An Example From a Middle Eastern Country
}

\author{
Jamal Zekri ${ }^{1}$ \\ ${ }^{1}$ Department of Oncology King Faisal Specialist Hospital and Research Centre, (Jeddah). College of Medicine, \\ Alfaisal University, Kingdom of Saudi Arabia \\ Correspondence: Jamal Zekri, Department of Oncology King Faisal Specialist Hospital and Research Centre, \\ (Jeddah), College of Medicine, Alfaisal University. Jeddah 21499. P.O. Box 40047, Kingdom of Saudi Arabia. Tel: \\ 966-53-312-9043; Fax: 966-12-667-7777 (Ext 64030). E-mail: jmzekri@hotmail.com
}

Received: February 20, 2018 Accepted: March 20, 2018 Online Published: March 24, 2018

doi:10.5539/gjhs.v10n4p127 URL: https://doi.org/10.5539/gjhs.v10n4p127

\begin{abstract}
Introduction: Most countries thrive to build and expand national research. Challenges may hinder clinical researchers and potential researchers particularly in developing countries. We aim to study some of these challenges in the Kingdom of Saudi Arabia (KSA).

Methods: A questionnaire reflecting possible challenges was completed by delegates and faculties of 5 cancer related educational scientific meetings.

Results: One hundred and forty seven responders were practicing in KSA and are the subject of this report. Ninety five $(64.6 \%)$ were physicians. While $122(83 \%)$ are interested in conducting research, service commitments and inadequate time, process of research approval within the department and obtaining financial funding were the most frequent challenges reported by $86(58.5 \%), 61(41.5 \%)$ and $53(36.1 \%)$ of responders.

Conclusion: Major challenges hinder clinical research development. The identified challenges need to be seriously addressed if advances in clinical research are to be expected.
\end{abstract}

Keywords: clinical research, challenges, Middle East

\section{Background}

Research and innovation have played a major role in the advancement of evidence based clinical practice globally. Developed countries including those in Northern American and Western European continents contribute to majority of such advancements through research and publications ("SJR - International Science Ranking," n.d.).

Clinical research is a complex multi-step process and thus the challenges are equally multiple and may include compliance with expanding regulations, obtaining funding, seeking necessary approvals including that of the Institutional Review Board (IRB), establishing legal agreements with sponsors and other investigators, complicated informed consent process, excessive bureaucracy and intense targets to deliver more routine service leading to inadequate time that might be utilized for research.

These obstacle are deterring many potential investigators from conducting clinical research (English, Lebovitz, Giffin, \& Institute of Medicine (U.S.). 2010).

The quality and quantity of clinical research in developing countries lags behind that of developed wealthier nations (Lang et al., 2010). This is likely to be due to the above challenges and probably many others. These challenges and the personal interest of health care professionals (HCPs) to conduct research are not well studied in the Middle East.

The Kingdom of Saudi Arabia (KSA) is a Middle Eastern (ME) country with relatively plentiful resources in comparison with other ME countries. Over the recent couple of decades, KSA has made impressive strides to raise the level of education, health services, academia and research (Deleu, Northway, \& Hanssens, 2001).

This study aims to investigate the challenges facing clinical research in the KSA.

\section{Methods}

This is a questionnaire based study. The questionnaire was designed by the investigator reflecting his own views 
and experience on the possible challenges that may face researchers and potential researchers. It is comprised of 6 close ended questions addressing personal interest in research, time, process feasibility and incentives (Table 1). Two other questions were aimed to identify the professional capacity and country of practice. Clarity and simplicity was attempted to guarantee maximum response. Paper copies of the questionnaire were hand presented personally to the delegates and faculties at 5 oncology related educational scientific meetings in KSA between March and December 2015. Duplication of response was avoided by asking potential participants if they have previously completed the questionnaire. Responders completed the questionnaire anonymously and without assistance. Data is analyzed and presented as simple frequencies. Chi-square test ( 2 sided significance $P$ value) was used to compare frequency of affirmative responses between physicians and non-physicians.

\section{Results}

Three hundred and fifty copies of the questionnaire were distributed. Two hundred and six (58.9\%) copies were completed and returned. Fifty nine responders were practicing in other Middle Eastern countries and are excluded from this analysis. One hundred and forty seven out of 206 (71.4\%) responders were practicing in KSA and are the subject of this report. The professional capacity of the 147 responders practicing in KSA were physicians, nurses, pharmacists and others in $95(64.6 \%), 31(21 \%), 11(7.5 \%)$ and $10(6.8 \%)$ respectively. Response to each question is depicted in table 1 showing service commitment and inadequate time, process of research approval within the department and obtaining financial funding were the most frequently reported challenges by $86(58.5 \%), 61$ $(41.5 \%)$ and $53(36.1 \%)$ of responders.

There was statistically different responses to questions about interest in research, process of obtaining funding and rewarding between physicians and non-physicians (Table 2).

Table 1. Response to the questionnaire by 147 responders who practice in Kingdom of Saudi Arabia

\begin{tabular}{|c|c|c|c|}
\hline Question & Yes $(\%)$ & No $(\%)$ & Don’t Know (\%) \\
\hline Do you have personal interest in conducting research? & $122(83)$ & $22(15)$ & $3(2)$ \\
\hline $\begin{array}{l}\text { Does your service commitment allow you enough time to conduct } \\
\text { research? }\end{array}$ & $52(35.4)$ & $86(58.5)$ & $9(6.1)$ \\
\hline $\begin{array}{l}\text { Do you find the process of approving a research project within your } \\
\text { department is feasible and reasonable? }\end{array}$ & $72(49)$ & $61(41.5)$ & $14(9.5)$ \\
\hline $\begin{array}{l}\text { Do you find the process of submission to and review by the institutional } \\
\text { review board is feasible and reasonable? }\end{array}$ & $70(47.6)$ & $41(27.9)$ & $36(24.5)$ \\
\hline $\begin{array}{l}\text { Is the process of obtaining financial funding for research feasible and } \\
\text { reasonable? }\end{array}$ & $57(38.8)$ & $53(36.1)$ & $37(25.2)$ \\
\hline Should staff active in research and academia be rewarded accordingly? & $119(81)$ & $14(9.5)$ & $14(9.5)$ \\
\hline
\end{tabular}

Table 2. Frequency of affirmative response to the questionnaire in physicians and non-physicians (after exclusion of "Don't Know" responses)

\begin{tabular}{llll}
\hline & $\begin{array}{l}\text { Physicians } \\
(\mathrm{n}=95)\end{array}$ & $\begin{array}{l}\text { Non physicians } \\
(\mathrm{n}=52)\end{array}$ & $\begin{array}{l}\text { Chi-square } \\
\text { P value }\end{array}$ \\
\hline $\begin{array}{l}\text { Do you have personal interest in conducting research? } \\
\begin{array}{l}\text { Does your service commitment allow you enough time to conduct } \\
\text { research? }\end{array}\end{array}$ & $34 / 89(38.2 \%)$ & $18 / 49(36.7 \%)$ & 1.00 \\
$\begin{array}{l}\text { Do you find the process of approving a research project within your } \\
\text { department is feasible and reasonable? }\end{array}$ & $48 / 89(53.9 \%)$ & $24 / 44(54.5 \%)$ & 1.00 \\
$\begin{array}{l}\text { Do you find the process of submission to and review by the institutional } \\
\text { review board is feasible and reasonable? }\end{array}$ & $43 / 73(58.9 \%)$ & $27 / 38(71.1 \%)$ & 0.223 \\
$\begin{array}{l}\text { Is the process of obtaining financial funding for research feasible and } \\
\text { reasonable? }\end{array}$ & $27 / 68(39.7 \%)$ & $30 / 42(71.4 \%)$ & 0.002 \\
\begin{tabular}{l} 
Should staff active in research and academia be rewarded accordingly? \\
\hline
\end{tabular} & $71 / 84(84.5 \%)$ & $48 / 49(98 \%)$ & 0.017 \\
\hline
\end{tabular}




\section{Discussion}

\subsection{Personal Interest in Conducting Clinical Research}

One of the most important factors that can ignite the initiation of any work is personal interest. Results of a questionnaire addressed to 2090 teaching academics in Australia identified interest and involvement (referred to as engagement) as important dimensions to satisfactory research performance (Bazeley, 2010).

Majority of participants in a mixed methods approach (surveys, focus groups, interviews) study of physicians in New York expressed interest in research ranging from research facilitation to serving as a site investigator for multi-site clinical trials (Bakken, Lantigua, Busacca, \& Bigger, 2009).

Similarly, majority of responders $122(83 \%)$ in our study expressed interest in conducting clinical research. It is possible that HCPs with interest in research were more likely to respond to our survey. Regardless, this interest and enthusiasm is a major impetus to further investigate possible challenges and heavily invest to overcome them.

We did not investigate the reasons for personal interest in research. Warkentin KD et al reported that enthusiasm for research is promoted by passion for learning, opportunities for collaboration, support, confidence, overcoming research challenges, research visibility and realizing the impact of research. They also reported that research related challenges and the invisibility of research served to diminish enthusiasm (Warkentin, Popik, Usick, \& Farley, 2014).

\subsection{Time Limitation}

Opportunity and resources including time as part of a supportive institutional environment are necessary (albeit often not sufficient) and need to be arranged and provided if research of any significance is to occur (Bazeley, 2010).

Patients' expectations continue to rise leading to pressure on HCPs to do more and spend more time in providing direct patient care mostly in service setting. Private, public and academic health institutions appreciate the key value of achieving patients' satisfaction through meeting their expectations. Thus, most institutions focus on setting service oriented objectives and targets to motivate HCPs to meet Patients' expectations. The resulting outcome is less time available for research activities. In extreme case, this may lead to demotivating HCPs from pursuing research. Lack of time and busy service related practice have long been recognized as an impediment to accruing patients in clinical trial (Foley \& Moertel, 1991; Smyth et al., 1994).

A comprehensive systematic study published in 1999 identified lack of time as a major barrier to clinicians' participation in randomized controlled trials (Ross et al., 1999). A report by the Institute of Medicine identified lack of time as the first challenges facing investigators even in academic health centers (English et al., 2010).

Recent literature indicate that lack of time remains a global obstacle (Bakken et al., 2009; Ito-Ihara et al., 2013; Rahman et al., 2011).

More than half of responders (58.5\%) to our questionnaire were clearly adamant that their service commitment doesn't allow enough time to conduct research. Another $6.1 \%$ of responders were not sure if they have enough time for research (table 1). On one side, this result can be considered as potentially alienating two thirds of clinical task force away from research. On the other hand, it can be appreciated as a positive outcome as $35 \%$ have enough time to conduct research. The latter is clearly not an ambitious perception if more research output is desired keeping in mind the modest research conducted in the ME region in general (Siddiqi, Stoppani, Anadon, \& Narayanamurti, 2016).

Health institutions should develop strategies through which clinical service providers can engage in research. This may be in the form of identifying research leaders (RLs) representing various disciplines. The RLs will be offered time away from service commitment to plan and conduct structured research. In return, the RLs are obliged to show satisfactory research output. Such strategy can be developed at the national level to guarantee widespread implementation and subsequent rich research productivity. The consultant job plan negotiated by the British Medical Association (BMA) and the UK National Health Service (NHS) reflects such approach. It states that consultants and managers should consider additional activities such as research when reviewing individual job plans (BMA, 2011).

\subsection{Process}

Over recent decades and since the declaration of Helsinki in 1964, there has been exponential proliferation of regulations affecting the conduct of clinical research.

There are 2 types of research processes, namely scientific and logistic. The steps of the scientific process include 
selection of topic, assessing scientific merits, literature search, setting hypothesis, designing the study, sampling, data collection, data analysis, hypothesis testing, interpretation and reporting. Our study was not designed to address challenges with these steps.

The steps of logistic research process include preliminary negotiations around the research idea in terms of, team interest, funding, feasibility and practicalities. The potential investigator will move to subsequent steps once these initial steps receive positive feedback. The next step is obtaining primary approvals of the division, section, department and/or manager which may involve lengthy presentations and detailed discussions. These administrative bureaucracies and the lengthy approval process have been identified as barriers to conducting clinical research in a qualitative content analysis conducted in Iran (Bahadori et al., 2014).

Only half of responders (49\%) reported that the process of approving a research project within the department is feasible and reasonable. This indicates that many departments may need to review this step to make it more feasible and less obstructive.

Clinical research involving human participants should be reviewed and research ethics approval obtained prior to starting the project. Health institutions have local and/or regional research ethics committees (REC), also known as institutional review boards (IRB).

A REC/IRB is composed of a group formally designated to protect the rights, safety and well-being of humans involved in clinical research guided by national and international laws. The group scrutinize all aspects of the study and grant approval if appropriate.

The step of application to and communication with REC/IRB can be a daunting experience to many investigators. Difficulties in communication with REC/IRB was reported by $68 \%$ and $24 \%$ of doctors in Kyoto and Seoul University Hospitals respectively (Ito-Ihara et al., 2013).

More than quarter of responders (27.9\%) in our study expressed their views that the process of submission to and review by the IRB is not reasonable. In addition, another quarter $(24.5 \%)$ were not able to comment indicating probable lack of communication with IRB or that they do not know or understand what the IRB expects of them.

A report by the Institute of Medicine acknowledges the complex internal requirements of academic institutions and federal agencies to review multiple aspects of a clinical research leading to delay in its initiation. At many times, IRBs are used for risk management above and beyond what is required for human subjects' protection. The report lists the top 4 barriers to clinical research as follow: (a) Ethical/IRB approval (b) scientific review/protocol approval (b) interaction with industry and issues with technology transfer (c) adequacy of resources. The IRB decision-making process can lack timeliness and accountability. One of the experts commented that a key concern is that IRBs are accountable only to their own institution and not to the greater public good suggesting that IRBs should be held accountable to the community for the decisions they make. Another expert commented on the human factor in some of IRB decisions leading to inconsistencies (English et al., 2010).

Which research projects need to be submitted to IRB and which do not? There is no clear answer and most IRBs do not entertain this question. The position of most IRBs is that any project that may remotely be interpreted as research has to be submitted to IRB for review and subsequent decision whether to be exempted or not. The IRB tends to not consider the exhaustive and potentially futile preliminary steps required prior to submission to IRB. Such approach is certainly illogical and unnecessarily time and effort consuming. Examples of projects that do not carry any risk to human and thus unlikely need submission to IRB include: (a) Research conducted in established educational settings, involving usual educational practices, such as research on the effectiveness of instructional techniques or curricula. (b) Research involving survey procedures, interview procedures or observation of public behavior. (c) Quality improvement projects even those of clinical nature such as rate of implementation of guidelines and standards (clinical audits), patients' satisfaction with services and research into assessing the outcome of organizational clinical services (d) Research involving the collection or study of existing data, documents, records, pathological specimens, or diagnostic specimens, if the information is recorded by the investigator in such a manner that subjects cannot be identified, directly or through identifiers linked to the subjects (Columbia University, n.d.).

A mixed methods approach (surveys, focus groups, interviews) was conducted among a sample of ambulatory care Research network clinicians from New York. This mixed approach allowed participants to express their experience with IRBs in their own words. The results highlight the seriously negative experience investigators endure when communicating with the IRB. One respondent explained how he/she had to go through multiple stages of communication, getting help to try to comply with the process and eventually he/she dropped the project as a consequence of multiple hurdles by the IRB. Another respondent explained how the communication with the IRB 
was lengthy and exhaustive despite the simple (no drug intervention) nature of the project (Bakken et al., 2009).

The European clinical trials directive was criticized as having excessive bureaucracy (Hunter, 2011).

Researchers in the European Union (EU) have for years demanded change to this directive arguing that it has contributed to a $25 \%$ reduction in clinical trials activities. In 2012, the European Commission outlined a new proposal of clinical-trials legislation. Agreement was reached and a legislation was published in May 2014 in the official journal of the EU (Legislation, 2014).

There is real need at the political level to review the excessive legal and ethical hurdles that are hindering effective clinical research. Despite multiple attempts, it is seems that achieving the right balance between strict legislation and further expansion of clinical research remains a mirage. Saying that, institutions, IRBs and other research regulatory bodies should consider the detrimental consequences of excessive bureaucracy and red tape on the future of medical development.

\subsection{Resources and Funding}

Health research can be very costly and financial returns are not guaranteed. Most of the research scientific institutions and communities have experienced strict spending limitations mandated by local or national budget control. The recent decade have witnessed an almost global recession with even more financial restrictions felt most by academic institutions dependent on governmental funding.

A report by the Institute of Medicine reported that in some cases, the National Institute of Health (NIH) pays research sites $20-40 \%$ less than the actual cost of conducting trials. It also suggested that there is inequality of NIH payments to research sites across the various NIH institutes (English et al., 2010).

Obtaining financial funding for research is dependent on the presence of funding bodies which could be governmental, charitable or industry linked. Equally important is the presence of clear application systems. These arrangements may not be well established in an environment that lacks a rooted research heritage (Bahadori et al., 2014).

More than a third (36.1\%) of responders to our questionnaire found that the process of obtaining financial funding for research is not feasible or reasonable. Another $25.2 \%$ were unable to comment reflecting either inadequate funding or lack of clear funding systems.

Inadequate funds for research seems to be a global issue. A white paper by the Joint Committee of the Nordic Medical Research Councils reports that the funding for medical research infrastructures is inadequate. In addition, public financial support for investigator-driven clinical trials is too limited (The Joint Committee of the Nordic Medical Research Councils., 2011). Inadequate funding was reported by $79 \%$ and $49 \%$ of doctors in Kyoto and Seoul University Hospitals respectively (Ito-Ihara et al., 2013).

For many decades, it was identified that there was no designated mechanism to fund clinical trials in the UK National Health Service (NHS) (Smyth et al., 1994).

Currently, the UK national institute for health research participates in funding of health research in the NHS. Saying that, shortage of bio-research funding remains a challenge as highlighted by the 2014 Nuffield Council on Bioethics report (Nuffield Council on Bioethics Steering Group, 2014).

Research funding bodies have recently been founded in KSA. Some of them liaise with universities, research centres and hospitals to support clinical research. King Abdulaziz City for Science and Technology (KACST) is a scientific governmental institution that supports scientific applied research. The mechanisms of funding offered by these bodies may need to be better advertised and streamlined. Equally important they should ensure feasibility, practicality, consistency and sustainability if they are to appeal to the scientific community.

The role of the health institutions such as hospitals in providing a working research environment is of paramount importance. Hospitals need to negotiate the building, sustaining and developing adequate infrastructure for medical and clinical research.

\subsection{Incentivizing and Rewarding Research Staff}

Monetary incentives (such as performance-based bonuses and increase in basic pay) are recognized as effective motivators to productivity and innovation (Lotfi, n.d.).

Non-monetary incentives (such as genuine praise and professional promotion) may also be effective.

There is evidence that this applies to health services. The Quality and Outcomes Framework incentive payments were found to be a cost-effective use of resources in the UK NHS primary care practices (Walker et al., 2010). 
Incentives seem to improve physicians' participation compared to no incentives even for contribution in a simple one off online survey based research (Young et al., 2015).

Job descriptions and career development pathways of HCPs working in academic roles provide enough incentives to heavily engage in research. Many universities in KSA provide monetary incentives to academicians who participate in completed projects. Needless to say, academic promotion is also linked to measurable research achievements. This is not necessarily the case for HCPs working in service provision roles who find it difficult to justify spending time and effort to participate in research unless there is reasonable incentive (Bakken et al., 2009).

We did not ask participants if rewarding programs exist at their institutions. However, they sent a clear message when $81 \%$ had the opinion that staff active in research should be rewarded.

Participants in a qualitative study conducted in a medical sciences institute in Iran expressed that lack of personal financial incentives can deter physicians from spending time and effort in research (Bahadori et al., 2014). In contrast, the introduction of an objective research incentive program stimulated productivity and was appreciated by the faculty in the university of Virginia (Schroen, Thielen, Turrentine, Kron, \& Slingluff, 2012).

The issue of reimbursing HCPs for participation in research is complicated in environments where clinical research enterprise is separate from traditional clinical practice as in the United States of America (USA). It is even more complicated when private practice physicians have disincentives to recruit their patients in clinical trials or refer them to be treated in academic research setting (English et al., 2010).

Incentive programs should be developed at local and/or national levels to encourage HCPs to participate in good quality research. They have to include different incentive schemes acknowledging the diverse preference of reward concepts by HCPs. The programs must be analyzed periodically against the performance objectives in order to develop better future programs as required

\subsection{Physicians and Non-Physicians}

Health care provision is based on mixed-professional and team-based approaches. Non-physicians HCPs (NPHCPs) play their integral roles in providing many aspects of health care. Similar to physicians, the practice of NPHCPs is mostly guided by research findings and updates. Thus, involvement of NPHCPs in research is necessary for the development of better comprehensive health care. We are not aware of any studies that compared research perspectives of different HCPs groups.

Our results show that high proportion (74\%) of NPHCPs are interested in conducting research. Recognizing and fostering this interest can have a positive impact on clinical research and health service.

Physicians and NPHCPs share similar level of challenges related to lack of time and research approval process (table 2). However, less physicians (39.7\%) view that the process of obtaining financial funding for research feasible and reasonable. The questionnaire was not designed to explore the reasons behind different participants' views. We can only speculate that this difference may reflect different levels of research involvement among physicians and NPHCPs in this study.

The relatively small numbers of NPHCPs sub-entities [nurses 31 (21\%), pharmacists $11(7.5 \%)$ and others 10 $(6.8 \%)]$ doesn't allow further subgroup analysis. Few studies investigated challenges facing NPHCPs in developing countries (Etowa et al., 2016; Fakeye, Adisa, Olukotun, \& Morawo, 2017; Tan \& Hatah, 2017; Torres et al., 2016). To study differences in perspectives, future studies should include large cohorts of different HCPs entities.

\section{Conclusion}

Majority of HCPs are interested in conducting research. However, service commitments, inadequate time, tedious research approval process and financial funding limitations are frequent challenges.

These identified challenges are likely hindering clinical research development and thus need to be seriously addressed if advances in clinical research are to be expected.

\section{Acknowledgments}

None relevant

\section{Funding}

This project did not receive any financial funding.

\section{Competing Interests Statement}

The author declares no conflict of interest. 


\section{References}

Bahadori, M., Momeni, K., Ravangard, R., Yaghoubi, M., Alimohammazdeh, K., Teymourzadeh, E., \& Mehrabi Tavana, A. (2014). Challenges of the health research system in a medical research institute in Iran: A qualitative content analysis. Global Journal of Health Science, 7(1), 69-78. https://doi.org/10.5539/gjhs.v7n1p69

Bakken, S., Lantigua, R. A., Busacca, L. V, \& Bigger, J. T. (2009). Barriers, enablers, and incentives for research participation: a report from the Ambulatory Care Research Network (ACRN). Journal of the American Board of Family Medicine: JABFM, 22(4), 436-45. https://doi.org/10.3122/jabfm.2009.04.090017

Bazeley, P. (2010). Conceptualising research performance. Studies in Higher Education, 35(8), 889-903. https://doi.org/10.1080/03075070903348404

BMA. (2011). A guide to consultant job planning. Retrieved from http://www.nhsemployers.org/ /media/Employers/Publications/Guide_to_consultant_job_planning.pdf

Columbia University. (n.d.). What needs to be submitted to the IRB. Retrieved June 22, 2017, from http://www.columbia.edu/cu/irb/policies/Efficient_IRB_Review_040113.html

Deleu, D., Northway, M. G., \& Hanssens, Y. (2001). Geographical distribution of biomedical publications from the Gulf Corporation Council countries. Saudi Medical Journal, 22(1), 10-2. Retrieved from http://www.ncbi.nlm.nih.gov/pubmed/11255602

English, R. A., Lebovitz, Y., Giffin, R. B., \& Institute of Medicine (U.S.). Forum on Drug Discovery, D. (2010). Transforming clinical research in the United States: challenges and opportunities: workshop summary. National Academies Press. Retrieved http://www.columbia.edu/cu/irb/policies/Efficient_IRB_Review_040113.html

Etowa, J., Aston, M., Vukic, A., Boadu, N. Y., Helwig, M., Macdonald, D. Diorgu, F. (2016). Experiences of nurses and/or midwives in research production in low- and middle-income countries. JBI Database of $\begin{array}{lllll}\text { Systematic Reviews and Implementation } & \text { Reports, }\end{array}$ https://doi.org/10.11124/JBISRIR-2016-003050

Fakeye, T. O., Adisa, R., Olukotun, R. T., \& Morawo, P. K. (2017). Hospital and community pharmacists' perception of the scope, barriers and challenges of pharmacy practice-based research in Nigeria. Pharmacy Practice, 15(1), 881-881. https://doi.org/10.18549/PharmPract.2017.01.881

Foley, J. F., \& Moertel, C. G. (1991). Improving accrual into cancer clinical trials. Journal of Cancer Education: The Official Journal of the American Association for Cancer Education, 6(3), 165-73. https://doi.org/10.1080/08858199109528114

Hunter, P. (2011). The health of European medical research. Attempts are under way to update EU regulations, with the aim of harmonizing clinical research across the continent. EMBO Reports, 12(2), 110-2. https://doi.org/10.1038/embor.2010.212

Ito-Ihara, T., Hong, J.-H., Kim, O.-J., Sumi, E., Kim, S.-Y., Tanaka, S. Yokode, M. (2013). An international survey of physicians regarding clinical trials: a comparison between Kyoto University Hospital and Seoul National University Hospital. BMC Medical Research Methodology, $13(1), \quad 130$. https://doi.org/10.1186/1471-2288-13-130

Lang, T. A., White, N. J., Tran, H. T., Farrar, J. J., Day, N. P. J., Fitzpatrick, R., ... Marsh, K. (2010). Clinical research in resource-limited settings: enhancing research capacity and working together to make trials less complicated. PLoS Neglected Tropical Diseases, 4(6), e619. https://doi.org/10.1371/journal.pntd.0000619

Legislation. (2014). Regulation (EU) No 536/2014 of the European Parliament and of the Council of 16 April 2014 on clinical trials on medicinal products for human use, and repealing Directive 2001/20/EC. Official Journal of the European Union, 57, 1-76. Retrieved from http://eur-lex.europa.eu/legal-content/EN/TXT/PDF/?uri=OJ:L:2014:158:FULL\&from=EN

Lotfi, Z. (n.d.). How incentive payments encourage innovation? A meta-analysis study. Presented at DRUID15, June 15-17, 2015. Retrieved from http://druid8.sit.aau.dk/acc_papers/jjv4u7cfv06f55nl0y0if5rv5951.pdf

Nuffield Council on Bioethics Steering Group. (2014). The Culture of Scientific Research In The UK. Retrieved from http://nuffieldbioethics.org/wp-content/uploads/Nuffield_research_culture_full_report_web.pdf

Rahman, S., Majumder, M. A. A., Shaban, S. F., Rahman, N., Ahmed, M., Abdulrahman, K. Bin, \& D’Souza, U. J. 
(2011). Physician participation in clinical research and trials: issues and approaches. Advances in Medical Education and Practice, 2, 85-93. https://doi.org/10.2147/AMEP.S14103

Ross, S., Grant, A., Counsell, C., Gillespie, W., Russell, I., \& Prescott, R. (1999). Barriers to participation in randomised controlled trials: a systematic review. Journal of Clinical Epidemiology, 52(12), 1143-56. Retrieved from http://www.ncbi.nlm.nih.gov/pubmed/10580777

Schroen, A. T., Thielen, M. J., Turrentine, F. E., Kron, I. L., \& Slingluff, C. L. (2012). Research incentive program for clinical surgical faculty associated with increases in research productivity. The Journal of Thoracic and Cardiovascular Surgery, 144(5), 1003-9. https://doi.org/10.1016/j.jtcvs.2012.07.033

Siddiqi, A., Stoppani, J., Anadon, L. D., \& Narayanamurti, V. (2016). Scientific Wealth in Middle East and North Africa: Productivity, Indigeneity, and Specialty in 1981-2013. PloS One, 11(11), e0164500. https://doi.org/10.1371/journal.pone.0164500

$\begin{array}{lllllll}\text { SJR-International } & \text { Science } & \text { Ranking. } & \text { (n.d.). Retrieved June 22, 2017, from }\end{array}$ http://www.scimagojr.com/countryrank.php

Smyth, J. F., Mossman, J., Hall, R., Hepburn, S., Pinkerton, R., Richards, M., ... Box, J. (1994). Conducting clinical research in the new NHS: the model of cancer. United Kingdom Coordinating Committee on Cancer Research. BMJ (Clinical Research Ed.), 309(6952), 457-61. Retrieved from http://www.ncbi.nlm.nih.gov/pubmed/7920132

Tan, S. Y., \& Hatah, E. (2017). Knowledge, attitudes, practices, and barriers related to research utilization: a survey among pharmacists in Malaysia. International Journal of Clinical Pharmacy, 39(2), 450-458. https://doi.org/10.1007/s11096-017-0425-7

The Joint Committee of the Nordic Medical Research Councils. (2011). Nordic White Paper on Medical Research. Present Status and Future Potential for Medical Research in the Nordic Countries. Retrieved from file:///C:/Users/J64677/Downloads/NOS_M_Medical Research in the Nordic Countries-1 (2).pdf

Torres, G. C. S., Estrada, M. G., Sumile, E. F. R., Macindo, J. R. B., Maravilla, S. N., \& Hendrix, C. C. (2016). Assessment of Research Capacity among Nursing Faculty in a Clinical Intensive University in The Philippines. Nursing Forum. https://doi.org/10.1111/nuf.12192

Walker, S., Mason, A. R., Claxton, K., Cookson, R., Fenwick, E., Fleetcroft, R., \& Sculpher, M. (2010). Value for money and the Quality and Outcomes Framework in primary care in the UK NHS. The British Journal of General Practice: The Journal of the Royal College of General Practitioners, 60(574), e213-20. https://doi.org/10.3399/bjgp10X501859

Warkentin, K. D., Popik, K., Usick, R., \& Farley, T. (2014). Fostering enthusiasm for research: Insights of undergraduate nursing students. Journal of Nursing Education and Practice, 4(5), 23. https://doi.org/10.5430/jnep.v4n5p23

Young, J. M., O’Halloran, A., McAulay, C., Pirotta, M., Forsdike, K., Stacey, I., \& Currow, D. (2015). Unconditional and conditional incentives differentially improved general practitioners' participation in an online survey: Randomized controlled trial. Journal of Clinical Epidemiology, 68(6), 693-7. https://doi.org/10.1016/j.jclinepi.2014.09.013

\section{Copyrights}

Copyright for this article is retained by the author(s), with first publication rights granted to the journal.

This is an open-access article distributed under the terms and conditions of the Creative Commons Attribution license (http://creativecommons.org/licenses/by/4.0/). 